\title{
Female Malignant Nipple Neoplasm
}

National Cancer Institute

\section{Source}

National Cancer Institute. Female Malignant Nipple Neoplasm. NCI Thesaurus. Code C120455.

A malignant neoplasm that affects the area of the nipple in females. 